\title{
Romanian customers' satisfactions regarding private health services
}

\author{
Andreea MARIN-PANTELESCU \\ Bucharest University of Economic Studies, Bucharest, Romania \\ marin.andreea@com.ase.ro \\ Mihaela HINT \\ 1 Decembrie 1918 University Alba Iulia, Alba Iulia, Romania \\ mihacont73@gmail.com
}

\begin{abstract}
Nowadays customers become more concerned about private health services, as performance, innovation and creativity overspread into our lives. Digital health services development in Romania has grown gradually through the acquisition of state-of-the-art equipment as RMN Siemens Magnetom Essenza machine, CT Optima 520 available in Romanian health private clinics. Is the e-health the future of health services in Romania? The answer will be a strong yes. Immunotherapy has revolutionized cancer treatment by leveraging the immune system to fight tumors. The hope is that someday immunotherapy options will exist for all types of tumors. On the other hand, 3-D printing allows the user to create health products specific to the patient, including prosthetics, implants, and airway stents. More than that, Virtual reality/mixed reality applications have become popular in Romanian medical education. Robotic approaches to surgery are less invasive and faster, and are often associated with improved clinical outcomes, such as decreased recovery time and reduced pain. For example, the da Vinci Surgical System translates the surgeon's hand movements to smaller movements made by the robot inside the body, all visualized via laparoscopy. The da Vinci System has been used on more than 3 million patients globally. The present paper researched the Romanian customers' satisfactions regarding private health services. The sample size was 400 people, of which 168 males and 232 females, with an average age of 40 years old, all from the urban area, developed standard of living with an average income of 1,500 euro per month. The results have shown that Romanian customers are willing to pay for private health services more than 500 euro per year. Romanian customers had declared in proportion of $68 \%$ that are satisfied with the prices of private healthcare networks, in proportion of $79 \%$ that are satisfied with the medical services offered by the private healthcare networks. In what it concerns the surgery performed by robots instead of doctors, only 45\% customers had declared in the robots favor. Further insights will be discussed in the research paper and concussions will be drawn reflecting the assessment of the Romanian customers' satisfaction regarding private health services.
\end{abstract}

Keywords: marketing, research, satisfaction, e-health, services.

\section{Introduction}

Health and medical care are of great significance for public health. Estimations indicate that health and medical care contribute several years to life expectancy (Creixans-Tenas and Arimany-Serrat, 2019). They also contribute perhaps even more to improving many people's functional ability and quality of life.

Beyond the phenomenon of poverty, however, a large part of the population in Romania has problems related to health education or with the health services they benefit from.

According to the OECD (Organization for Economic Cooperation and Development) the number of doctors working abroad exceeded 14,000 in 2013, representing $26 \%$ of the total number of doctors at the time, according to the report. Between 1991 and 2013, the departures of physicians increased nine times in intensity, with the largest wave recorded after 2000 . The figures show a 
shortage of health specialists which becomes increasingly obvious if we take into account that the number of doctors working in Romania increased by $18 \%$, while the number of those working abroad increased by more than $650 \%$. Also, over $50 \%$ of Romanian doctors working abroad are younger than 40 (OECD, Romania: Country Health Profile 2017).

In 2018, according to the National Institute of Statistics, there were 60,585 doctors, 515 hospitals in Romania, of which 368 public hospitals and 147 private hospitals, 4280 medical laboratories, out of which 2139 private medical laboratories. Of the total number of doctors in Romania, in 2018, 38,064 were employed in public hospitals and 22,521 were employed in private hospitals.

The offer is adapted to the demand for medical services, so in 2018 the total number of patients discharged from the hospital was 3,996,256. The illnesses of the Romanians and the crisis in the public health system (infections, misery, bad behavior towards patients from nurses) led the Romanians to private hospitals. According to the KeysFin study (2019), private medical services increased in 2018 compared to 2007, with almost 500\%.

Even though healthcare is free of charge for Romanian employees, more and more people choose to treat their health problems in the private system. In 2019, private companies in the medical sector have come to offer much of the services needed to the population, from medical analysis to complicated operations.

The main argument for the clients is the quality of the services. The comfort and highperformance equipment, the short waiting time, the attention given to hygiene, the professionalism of the employees are just a few of the elements, which put in balance with the intra-hospital infections and the lack of endowments from the state hospitals determined the Romanians to choose the alternative offered by the private hospitals and clinics.

Thus, the business in the private health services sector has reached, in 2018, the level of 11 billion lei, from 9.7 billion lei in 2017. According to the analysis of KeysFin, the business in this sector increased by $21.3 \%$ compared to 2016 , respectively $472 \%$ compared to 2007 . The net profit of the networks of private clinics increased by $29 \%$ compared to 2016 and by $420 \%$ compared to 2007, to 1.5 billion lei in 2017 .

In this paper we conducted a research of the satisfaction of the consumers of private medical services in Romania. Further insights will be discussed in the research paper and concussions will be drawn reflecting the assessment of the Romanian clients' satisfaction regarding private health services.

\section{Literature review}

The medical system and the media services are called pure services and are the most intangible and abstract because patients put all their trust in the doctor who operates and treats them (MarinPantelescu, 2009). Making a proper diagnosis and establishing a treatment plan is vital to the life of any of us. There is no subject more sensitive than health. We all want to live as long as possible and enjoy life.

There are extensive discussions in the literature, which system is better, more efficient, the private medical system or the public medical system (Bjorvatn, 2018; Oli, et al., 2016).

Doctors and nurses are the most important resources for health systems. They are also present in both the public and private systems. And they are subject to the rules of deontology: informed consent, professional secrecy, quality of medical act, patient safety, prophylaxis of malpraxis (AlNsour, 2017; Nor Khasimah and Wan Normila, 2016). 
The right to benefit from the highest standard of health is an obligation provided by human rights law (Olofsson, et al., 2019). Derived from the right to health, access to health services according to the needs of patients is a fundamental right.

In an ethical approach we observe that the health system is a concept that does not take into account the form of ownership (Olusanya, et al., 2010).

Some experts consider the private system an alternative to the public system (Alcantara, et al.,

PICBE $\mid 790$ 2019), and other authors argue that the public system is not in competition with the private system (Olusanya, et al., 2010; Cheol, et al., 2019; Werthman, 2018).

For a variety of reasons which include convenience, privacy, shorter waiting time, continuity of care, perceived service/delivery quality, empathy and availability of doctors as well as status symbol a high proportion of women in developing countries who have access to and can afford services provided by skilled personnel usually opt for services offered in private health facilities albeit at higher fees (Olusanya et al., 2010).

According to Creixans-Tenas and Arimany-Serrat (2019) the public health sector is characterized by having limited resources, an incessant increase in spending and in care needs (population aging, increase in chronic diseases) that causes endless waiting lists.

The private system is a complementary system, which has a limited area of activity, which comes to decongest the public system from a series of activities and absorbs a limited number of people (Wright, 2007; Vogus and McClelland, 2016; Gomez Martin, et al., 2019).

In 2016, Oli et al. have conducted a research study revealing that healthcare workers in government hospitals have more knowledge on healthcare waste management system than those in private hospitals.

Public hospitals are owned by a government entity and typically are not profit maximizers. Private hospitals, both for-profit and non-profit, may gain profit (Bjorvatn, 2018).

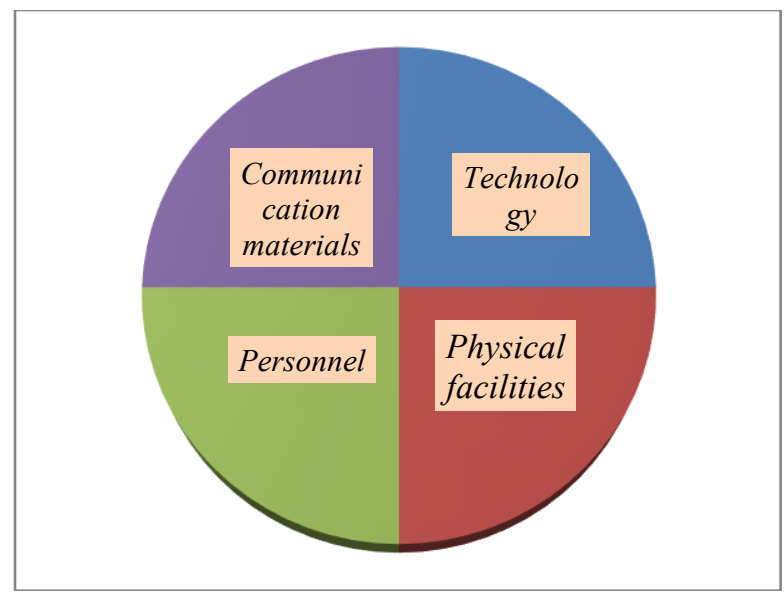

Tangible elements

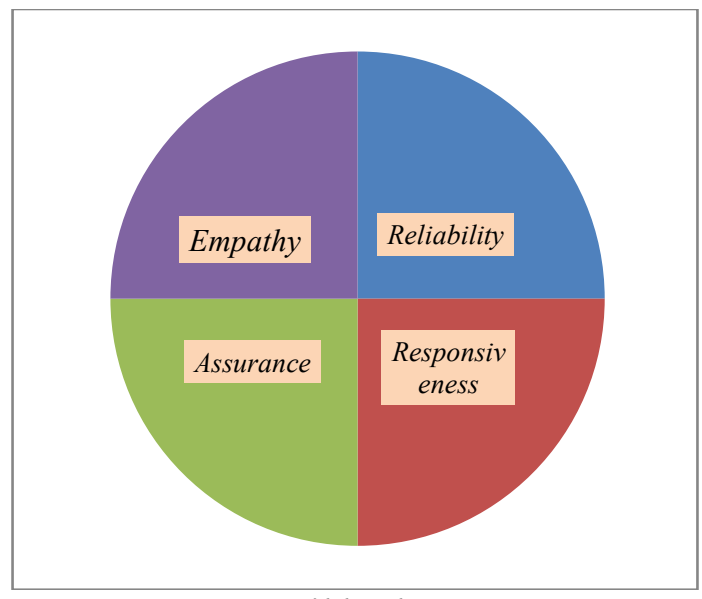

Intangible elements

Figure 1. Medical services quality determinants

Source: Authors' adapted after Nor Khasimah, A. and Wan Normila, M. (2016)

In principle, the development of the medical system (including the Romanian system) is primarily dependent on the level of funding and the efficiency with which this funding is used, the population structure and socio-economic development of the geographical area concerned, not at least the attitudes and expectations of patients, which in turn translate into policies adopted by the system. 
In the major urban areas, medical facilities are generally well-equipped, with world-class private healthcare also available. In rural areas and small towns, healthcare is sub-standard, with patients often asked to buy basic supplies such as gloves and syringes.

The market for private medical services in Romania is divided between three major players: Regina Maria, MedLife and Sanador.On the first place in the top of the business in the private medical sector in Romania at the level of 2018 we find Regina Maria, with a turnover of 381 million lei (3.9\% of the total market).

On the second place is MedLife, with a turnover of 379 million lei, and on the third place we find Sanador with 289.6 million lei turnover (3\% market share).

After Sanador we have the following private clinics Fresenius NephroCare, Diaverum, Synevo, Delta Health Care, Monza Hospital, and Gral Medical.

In a country where the natural increase is decreasing and the aging population has reached a worrying level, the need for medical services will be increasing. In the absence of substantial allocations for the construction of hospitals, clinics and the development of assistance services, it seems increasingly probable the alternative of including private medical services in the state medical insurance system. Thus, in the future, the state may need to use private clinics to cover its needs, and payments should be made from the public budget.

Technology makes its place in medicine and helps us extend our lives. Robotic approaches to surgery are less invasive and faster, and are often associated with improved clinical outcomes, such as decreased recovery time and reduced pain. Robotic approaches to surgery also guide surgeons in the operating room.

For instance, the da Vinci Surgical System, which is probably the best-known robotic surgery platform, translates the surgeon's hand movements to smaller movements made by the robot inside the body, all visualized via laparoscopy. The da Vinci System has been used on more than 3 million patients globally. Virtual reality/mixed reality (VR/MR) applications have become popular in medical education. VR/MR permits medical students to experience and learn from life-and-death scenarios in a low-stakes environment. 3-D printing allows the user to create health products specific to the patient, including prosthetics, implants, and airway stents.

December 2019 is the time when we experienced the COVID-19 pandemic, which caused severe acute respiratory syndrome devastating the planet. The coronavirus COVID-19 has affected 210 countries and territories around the world and 2 international conveyances. On April 15, 2020 there were 2,000,995 Coronavirus Cases with 126,783 Deaths, and 485,011 Recovered.

A new era and new challenges in the world of medicine dealing with the COVID-19 pandemic bring to the fore telemedicine and the virtual clinic for doctor-patient consultations. We consider the use of online consultations to be the future in telemedicine and certain evidence that medical services are interconnected with digitalization. A reference example is the Regina Maria Health Network, which implemented in time record, March 2020, together with Microsoft Romania "Regina Maria Virtual Clinic". Among the benefits of online consultations there are: online home consultation without going to the clinic to expose yourself to respiratory infections; availability on the phone, tablet or computer, real-time communication with the specialist doctor, services settled by the insurance companies, questions and prescription for the symptoms that bother you, consultation saved in the patient's medical history and access at any time to the medical report (Regina Maria, 2020).

\section{Methodology}

The research is quantitative, based on a questionnaire with closed questions, with only one answer. The research was carried out at the Romania's Tourism Fair organized by Romexpo 
Exhibition Center in the Hall B2. When tourists go on vacation they need medical insurance and seek medical services for various vaccines required for countries in Asia and Africa. We have relied on this information so that we can link the questions in the questionnaire and determine the visitors to answer us.

The event took place on November 14-17, 2019. The students from the Faculty of Business and Tourism, group 339, were interview guides. We relied on students for the questionnaires. In Romania's Tourism Fair from November 14-17, 2019, there were 14,000 registered visitors.

The construction of the research sample was performed using a random sampling method simple random sampling, the implementation of which led to the completion of 400 questionnaires, using the following formula:

$$
\mathrm{n}=\mathrm{t}^{2} * \mathrm{p}(1-\mathrm{p}) / \Delta \omega^{2}
$$

For a coefficient $t$ of 1.96 which corresponds to a probability of guaranteeing $95 \%$ results and an acceptable limit error of 5\%, the sample size is 384 questionnaires. For the sake of representativeness we decided to complete 400 questionnaires.

The answers were centralized and processed using SPSS Software version 16 (Statistical Package for the Social Sciences).

Regarding the demographical profile the sample size was 400 people, of which 168 males and 232 females, with an average age of 40 years old, all from the urban area, developed standard of living with an average income of 1,500 euro per month.

The limits and constraints in conducting the research were related to the fixed period of the event (4 days), to the fact that we had access to an event dedicated to tourism, but also to health through health tourism. Nevertheless, we believe that we have obtained a quite good representativeness, small errors being possible however.

The research hypotheses were as follows:

H1: Romanians are willing to pay for private health services

H2: Romanians are satisfied with the prices charged by private health networks

H3: Romanians are satisfied with the quality of the medical act performed in private hospitals

H4: Romanians are reluctant to be operated by a robot and still prefer to be operated by doctors.

\section{Results and discussions}

Analyzing the last visit to the private healthcare hospitals we asked clients to provide a score from 1 to 5, 1 meaning very unsatisfied and 5 meaning very satisfied.

The results below reflect the responses of 400 patients who used private health services and were registered between November 14 and 17, 2019.

Activity and involvement of the doctor gets the highest score (4.6) from the respondents. The private hospitals hunted the most trained doctors from the state hospitals and made them unrefusable offers. When people talk about the conditions in hospitals, they do not only refer to the cleanliness, the equipment or the facilities of the salons, but also to the way the medical personnel behave with them. Patient care, empathy, understandable explanations for all are things that people say they value most in private hospitals. The special attention that the doctors can give to each patient makes the Romanians come to the private system for surgery and treatment. On the other hand, we see a low score of 3.3 for the activity and involvement of the assistants even in the private system. They are not properly prepared to serve patients, to have patience, sometimes they think they are superior to doctors and consider themselves to be bosses in the coordinated ward. 
The cleanliness of the private hospitals and the facilities and the environment registered a score of 4.5, the professionalism of the front desk staff a score of 4.3 , the satisfaction with the medical services offered a score of 4.2 , the call center programming a score of 4.1 . These scores near maximum 5 make us think that there is room for improvement for the private system.

The natural question arises: how do we improve the private health system? Keeping the rod up, procedures developed and followed by the book, zero tolerance for bribes, patient loyalty, loyalty and respect for the medical team employed, attracting funds from European projects.

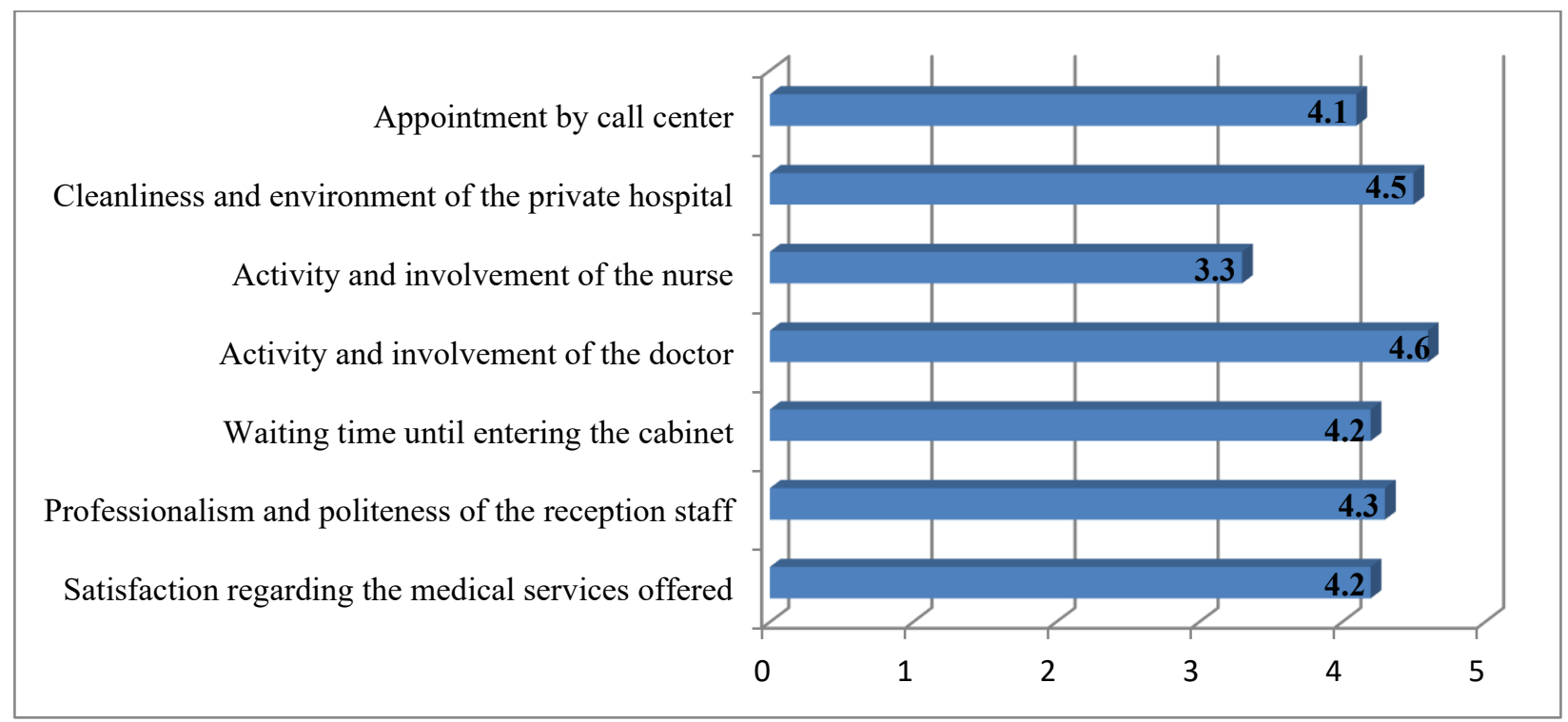

Figure 2. Romanian customers' satisfactions regarding private health services on a scale from 1 to 5

Source: Authors' own research

Hypothesis $\mathrm{H} 1$ is accepted given that Romanians are willing to pay for private health services. I agree to pay because I always find clean rooms and units equipped with state-of-the-art equipment, surgeons who have time to explain their operation and treatment, risks and recovery plan, quick programming and very short waiting time in front of the office. In fact, the waiting time in front of the office is vital for Romanians. They are a people who have no patience by the nature of national culture. With a score of 4.2 we claim that the respondents declare themselves satisfied with the waiting time until they enter the doctor's medical office. 


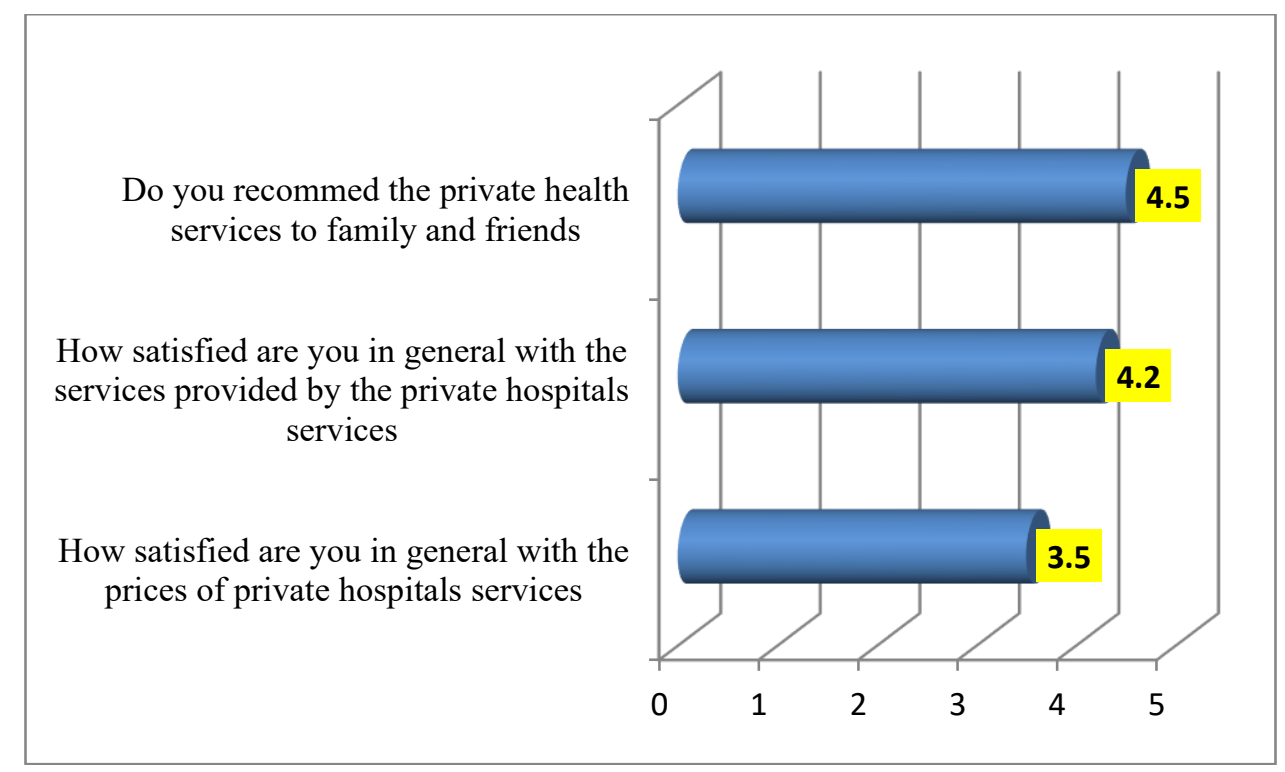

Figure 3. Romanian customers' satisfactions regarding private health services (overall assumptions)

Source: Authors' own research

Regarding the $\mathrm{H} 2$ hypothesis, the Romanians are satisfied with the prices charged by the private health networks, it is confirmed in moderation and we want to specify that the respondents gave a score of 3.5 .

We asked the respondents if they recommend private health services to family and friends and we asked them to choose 1 the lowest grade which means does not recommend and 5 the highest grade which means that they firmly recommend them. Using the semantic differential in 5 steps, we calculated the score for their answers and concluded that the respondents strongly recommend the private health services to relatives and friends. The score of 4.5 out of 5 maximum makes us support hypothesis H3 according to which Romanians are satisfied with the quality of the medical act performed in private hospitals and recommends also to family and friends to go for treatment in private networks.

Dissatisfied with the conditions in the state hospitals and with the lost confidence in the state health system, Romanians are treated in private hospitals. With the help of the health insurance company, which makes settlements based on a referral ticket from the family doctor, the Romanians who go to the private hospitals have settled part of the medical services provided by the medical specialist.

Corruption and bribery in the public health system, outdated apparatus and prolonged treatment, fear of intra-hospital infections are the main problems of the state health system. The care for the patient and his needs in the private system is much higher.

On a scale from 1-5, Romanians award 3.5 for the prices charged by private hospitals. Yes, they are high prices for the purchasing power of Romanians and for the living standards of most Romanians. And yet, Romanian customers had declared in proportion of $68 \%$ that they were satisfied with the prices of private healthcare networks. Many patients prefer to pay higher rates at private clinics and get rid of the stress of "putting in their pocket" something to nurses, doctors or anesthetists, and without fear that they will be treated less carefully because of this.

The results have shown that Romanian customers are willing to pay for private health services over 500 euro per year. Romanian customers had declared in proportion of $79 \%$ that they were 
satisfied with the medical services offered by the private healthcare networks. As far as the surgery performed by robots instead of doctors is concerned, only $45 \%$ of the clients had declared themselves to be favorable to the robots. This confirms the hypothesis H4, stating that the Romanians are still reluctant to be operated by a robot and still prefer to be operated by doctors.

Table 1. How satisfied are you with the prices of private healthcare networks in Romania

PICBE $\mid 795$

\begin{tabular}{|l|l|l|}
\hline & Answers & \% \\
\hline Satisfied & 272 & 68 \\
\hline Unsatisfied & 128 & 32 \\
\hline Total & 400 & 100 \\
\hline
\end{tabular}

Source: Authors' own research

In the private clinics, modern equipment is a guarantee of the quality of patient care. Also, private clinics attract valuable doctors by offering them much higher salaries as in the state owned hospitals, working conditions as in the West, cleaning, sterile space, medical substances necessary for the treatment of patients.

\section{Conclusion}

The results of the research show that the market for private medical services is growing and that the new generations are willing to pay for them. With an average annual growth rate of the population of minus $4 \%$, with a birth rate showing the lowest levels registered so far, private medical services will be increasingly used and sought. Our state health system is old, rusty, as from the third world.

Private health services have many advantages, including more professional, better, more involved doctors, the short waiting time for medical investigations: consultation and treatment, respect received from private medical staff, cleanliness and state-of-the-art equipment.

We have the opportunity to learn from the difficult situations we face in the case of the COVID19 pandemic, and to bring the technology together with medicine to ensure the health of patients. The Regina Maria Virtual Clinic is a prime example of this.

Private health networks have understood the powerful impact they have on people's lives and are trying to give them genuine care. Also, private health networks have entrepreneurial collaborations with companies based on integrity and lifelong learning.

The limits and constraints in conducting the research were related to the fixed period of the event (4 days), the fact that we had access to an event dedicated to tourism, but also to health through health tourism, with all these we believe that we have obtained a quite good representativeness, small errors being possible however.

\section{References}

Alcantara, J., Whetten, A., Ohm, J. and Alcantara, J. (2019). Ratings of perceived effectiveness, patient satisfaction and adverse events experienced by wellness chiropractic patients in a practice-based research network. Complementary Therapies in Clinical Practice, [ejournal], 36, pp.82-87, https://doi.org/10.1016/j.ctcp.2019.06.003.

Al-Nsour, I.A., (2017). WOM Effectiveness in Improving the Purchasing Behavior: Comparative Study on the Private Hospitals Inpatients in Jordan and Saudi Arabia. Arab Economic and Business Journal. [e-journal], 12, pp.13-28, http://dx.doi.org/10.1016/j.aebj.2017.04.003.

Bjorvatn, A.(2018). Private or public hospital ownership: Does it really matter?. Social Science \& Medicine, [e-journal], 196, pp.166-174, https://doi.org/10.1016/j.socscimed.2017.11.038. 
Cheol, K.O., Kwang, H.K., Wooju, J., Woong, K.H., Koon, H.R. and Bummo, A. (2019). Research on Patient Satisfaction of Robotic Telerounding: A Pilot Study in a Korean Population. Technology and Engineering, [e-journal], 130, pp.205-208, https://doi.org/10.1016/j.urology.2019.04.030.

Creixans-Tenas, J., Coenders, G. and Arimany-Serrat, N. (2019). Corporate social responsibility and financial profile of Spanish private hospitals. Heliyon, [e-journal], 5, https://doi.org/10.1016/j.heliyon.2019.e02623.

PICBE | 796

Gomez Martin, C., Garcia Morato, R.A., de los Reyes Cortes, N., Fernandez-Canamaque, J.L. and Holguin, P. (2019). Patient satisfaction in a Spanish burn unit. Burns, [e-journal], 45, pp.341-347, https://doi.org/10.1016/j.burns.2018.03.015.

KeysFin study (2019). https://www.keysfin.com/EN/\#!/Pages/News/KeysFin-BusinessStudies/Archive-studies.

Marin-Pantelescu A. (2009). Diversificarea si personalizarea serviciilor turistice in contextul globalizarii, Editura ASE, Bucureşti.

National Institute of Statistics (2019) National Statistical Yearbook and Tempo Online date series available at http://statistici.insse.ro:8077/tempo-online/.

Nor Khasimah, A. and Wan Normila, M. (2016). Linking Service Quality, Patients' Satisfaction and Behavioral Intentions: An investigation on Private Healthcare in Malaysia. Procedia Social and Behavioral Sciences, [e-journal], 224, pp.141-148, doi: 10.1016/j.sbspro.2016.05.419.

OECD, Romania: Country Health Profile

https://www.oecd.org/countries/romania/romania-country-health-profile-2017-

(2017). 9789264283534-en.htm.

Oli, A.N., Ekejindu, C.C., Adje, D.U., Ezeobi, I., Eijiofor, O.S., Ibeh, C.C. and Ubajaka, C.F. (2016). Healthcare waste management in selected government and private hospitals in Southeast Nigeria. Asian Pacific Journal of Tropical Biomedicine, [e-journal], 6(1), pp.84-89, http://dx.doi.org/10.1016/j.apjtb.2015.09.019.

Olofsson, P.T., Aspelin, P., Bohlin, J. and Blomqvist, L. (2019). The impact of contracts on outsourcing computed tomography examinations from a Swedish public university hospital to a private radiology unit. Radiography, [e-journal], 25, pp.148-154, https://doi.org/10.1016/j.radi.2018.12.014.

Olusanya, B.O., Roberts, A.A., Olufunlayo, T.F. and Inem, V.A. (2010). Preference for private hospital-based maternity services in inner-city Lagos, Nigeria: An observational study. Health Policy, [e-journal], 96, pp.210-216, doi:10.1016/j.healthpol.2010.02.002.

Regina Maria (2020). Clinica Virtuală Regina Maria, https://www.reginamaria.ro/clinica-virtuala, acceseed at 10.04.2020

Werthman, J.A. (2018). Patient Satisfaction, Nursing, and Radiology: A Review. Journal of Radiology Nursing, [e-journal], 37, pp.255-259, https://doi.org/10.1016/j.jradnu.2018.08.004.

Vogus, T.J. and McClelland, L.E. (2016). When the customer is the patient: Lessons from healthcare research on patient satisfaction and service quality ratings. Human Resource Management Review, [e-journal], 26, pp.37-49, http://dx.doi.org/10.1016/j.hrmr.2015.09.005.

Wright, D.J. (2007). Specialist payment schemes and patient selection in private and public hospitals. Journal of Health Economics, [e-journal], 26, pp.1014-1026, doi:10.1016/j.jhealeco.2007.02.002. 